\title{
SEGUROS SOCIALES Y CONFLUENCIAS DOCTRINALES EN ESPAÑA E ITALIA (1938-1944/47)
}

\author{
SOCIAL POLICIES AND DOCTRINAL CONFLUENCES \\ IN SPAIN AND ITALY (1938-1944/47)
}

\author{
Guillermo Marín* \\ UPV/EHU (España)
}

\begin{abstract}
RESUMEN: En este texto se analiza la labor desempeñada por las publicaciones emanadas del Instituto Nacional de Previsión español (INP) y del Istituto Nazionale (Fascista) della Previdenza Sociale italiano (INFPS), como instituciones difusoras de una concepción de los seguros sociales públicos con un marcado sesgo nacionalizador, y en línea con el perfil totalitario de ambas instituciones en parte de la cronología planteada. El objeto de estudio se enmarca, además, en un contexto europeo/internacional, el de inicios de los años $30 \mathrm{del} \mathrm{s}$. Xx, de vocación ensanchadora de los sistemas de previsión social públicos/nacionales en espacios de diversos colores políticos.

El estudio comparado del corpus editor de ambos entes hace asomar paralelismos notorios en líneas discursivas y pautas de actuación, tanto en la cronología central de análisis como en los años inmediatamente posteriores al final de la 2. ${ }^{\text {a }}$ Guerra Mundial, cuando ambos países se orientaron a una concepción de sus seguros sociales en línea con los planteamientos de William Beveridge.
\end{abstract}

PALABRAS CLAVE: Política social, Propaganda, Nacionalización, Falangismo, Fascismo.

ABSTRACT: This paper analyzes the work carried out by the publications issued by the Spanish Instituto Nacional de Previsión and the Italian Istituto Nazionale (Fascista) della Previdenza Sociale, as institutions that spread a conception of public social insurance with a notorious nationalizing essence, and according to the totalitarian profile of both institutions in the proposed chronology.

The comparative study of the publications of INP and IN $F) P S$ reveals important similarities in discursive lines and patterns of action, in the central chronology of analysis of the text and also in the years immediately after the end of the 2 nd World War, when both countries were oriented to a conception of their social insurance inspired by the ideas of William Beveridge.

KEYWORDS: Social policies, Propaganda, Nationalization, Falangism, Fascism.

\footnotetext{
* Correspondencia a: Guillermo Marín. Universidad del País Vasco/Euskal Herriko Unibertsitatea. Facultad de CC. Sociales y de la Comunicación. Departamento de Historia Contemporánea. Barrio Sarriena s/n, Leioa (Bizkaia) 48940 - guillermo. marin@ehu.eus - http://orcid.org/0000-0003-4565-6073
}

Cómo citar: Marín, Guillermo (2019). "Seguros sociales y confluencias doctrinales en España e Italia (1938-1944/47)»; Historia Contemporánea, 61, 775-796. (https://doi.org/10.1387/hc.20175).

Recibido: 9 septiembre, 2018; aceptado: 2 enero, 2019.

ISSN 1130-2402 - eISSN 2340-0277 / (C) 2019 UPV/EHU

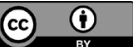




\section{Introducción. Un vistazo a las políticas sociales en Europa, tras la crisis de 1929}

En el curso de los años 30 del siglo xx, y como consecuencia de los efectos del crack de Wall Street, los sistemas políticos que se vieron afectados iniciaron una reflexión que pronto desembocó en discurso público. Esta reflexión apuntó a un mercado, abandonado a sí mismo, como la causa fundamental de la crisis. John Maynard Keynes fue uno de los primeros en diagnosticar el mal, y en prescribir un remedio suficientemente rompedor como para posibilitar un giro a las políticas económicas llevadas a cabo por los países capitalistas hasta entonces. Resumiendo, la clave de su propuesta se situó en otorgar a la mano visible y tangible de los gobiernos la misión de sacar a la economía de su estancamiento, mediante una salvaguarda del poder adquisitivo de la ciudadanía que posibilitara una absorción de los bienes y servicios existentes.

Esta idea, que fue calando en instituciones, sindicatos, partidos políticos, intelectuales y funcionarios públicos de diversos países, facilitó la puesta en marcha, en grados y de formas diversas, de una intervención económica estatal para reducir la miseria y crear las bases de la recuperación económica. Y fue, de hecho, base común sobre la cual actuaron tanto las democracias que buscaron redimirse y reformularse, como los regímenes totalitarios, que llevaron el intervencionismo estatal a su extremo.

Así, por un lado las democracias comenzaron a fijar su interés en los horizontes del pleno empleo, de una redistribución más equitativa de la riqueza, y en una serie de coberturas sociales destinadas al bienestar de la ciudadanía. El objetivo era transmitir una sensación tangible de inclusión de las clases subalternas en el perímetro de la ciudadanía mediante el reconocimiento de una serie de derechos sociales.

Mientras, en los regímenes totalitarios como Italia y Alemania (a la que hemos de sumar la España franquista previa al final de la segunda guerra mundial), se dio prioridad al dirigismo (puesto en marcha con mayor o menor habilidad por estos regímenes), a la lucha contra el desempleo como herramienta de consenso ideológico y para fortalecer al Estado, y al encuadramiento de las masas mediante la intervención directa en extensas esferas de las vidas de la ciudadanía (trabajo, vertebración familiar, tiempo libre, etcétera) ${ }^{1}$.

1 Molinero, 2005; Mattera, 2012. 
En clave europea - y dejando, por lo tanto, a un lado las dinámicas particulares del New Deal estadounidense-, fueron los países nórdicos los primeros que, arrastrados por la ola de la crisis, comenzaron la construcción de algo similar a lo que, en nuestros días, se entiende como un Estado Social. En un contexto de deslegitimación de la clase política dominante hasta entonces, los partidos socialdemócratas llegaron con fuerza a los gobiernos de Dinamarca y Suecia, en 1932, y de Noruega en 1935. Entre ellos, la historiografía europea ha situado el caso sueco como el más representativo de este «despertar del Welfare State / Estado del Bienestar».

Para el caso sueco, hasta la crisis del 29 y en lo que a políticas sociales se refiere, este país había oscilado entre la doctrina conservadora del laissez faire y experimentos ocasionales como la introducción parcial de pensiones de orientación universalista (1913). En 1932, con una tasa nacional de desempleo de más del 23\%, el partido socialdemócrata llegó al poder apoyado por el partido de los agricultores, formando un exitoso binomio que se mantuvo en el poder hasta los años 70. Se constituyó así un nuevo pacto social equilibrado entre las fuerzas de trabajo urbanas y agrícolas, las clases medias y la burguesía capitalista. Este pacto abrió al gobierno las puertas a una intervención en clave social. Tras una década convulsa, los sindicatos suecos llamaron a la paz a sus trabajadores. Mientras, la burguesía urbana concedió aumentos salariales en la industria y potenció una subida de precios de los productos agrícolas. Esta burguesía consintió también la inauguración de una intensa política fiscal estatal, que se orientó a financiar el empleo y a redistribuir la riqueza, para intentar acortar la distancia entre los más ricos y los más pobres. Las instituciones públicas se situaron en el centro de la vida nacional, priorizándose el ganar terreno al mercado para garantizar pensiones para todos los ciudadanos, independientemente de su salario y de sus cotizaciones ${ }^{2}$. Fue un consenso, en definitiva, que dio al Estado la potestad de ser social y de actuar, sin oposición, en favor del conjunto social.

Frente al «consenso espontáneo» de modelos como el sueco, los convulsos años 30 vieron aparecer y desarrollarse sistemas políticos totalitarios que, precisamente por su naturaleza antidemocrática, vertebraron proyectos políticos que implicaban la imposición de un consenso desde arriba, y a cualquier precio. En este sentido, se intentó que las «políticas

2 Esping-Andersen, 1990. 
sociales» de estos regímenes fueran un instrumento de homogeneización, de nacionalización, y de legitimación ${ }^{3}$. Poniendo, así, el intervencionismo social al servicio del fin último y más importante: el objetivo político de la difusión masiva de una ideología totalitaria planteada como ineludiblemente regeneradora ${ }^{4}$.

El desarrollo de estas políticas sociales ha tenido y tiene, independientemente de la naturaleza ideológica del sistema político del que emanan, un componente nacionalizador manifiesto y de sutileza variable según el contexto nacional e internacional en que se moldea, y el grado de instrumentalización al que se somete. Cuando el Estado, impulsado a ello por voluntades diversas, interviene en la cuestión social con consecuencias tangibles para la ciudadanía, este Estado gana legitimidad y apoyo social, pudiendo aderezar estas iniciativas con un discurso nacionalizador, conglomerador, legitimador, de uno u otro perfil. De esta forma se integra al conjunto de esa ciudadanía (o a importantes parcelas de esta) en un proyecto nacional común y cohesionador: un ciudadano paga impuestos para sostener un sistema de seguros sociales arbitrado por el Estado, con el que puede beneficiar a personas que este ciudadano jamás conocerá. Al mismo tiempo, otras personas también pagan impuestos de los que este ciudadano se podrá beneficiar, de uno $\mathrm{u}$ otro modo. Todo ello sucede en un espacio determinado, en un territorio acotado cuyo sentido se refuerza, que identifica a sus nacionales y une en su destino a sus integrantes. Estamos, pues, ante unos seguros sociales que operan como mecanismo vertebrador de primer orden para los Estados, en sus variadísimas versiones, durante el siglo Xx. En definitiva, una forma de solidaridad práctica y palpable entre nacionales que constituye una de las expresiones más eficaces, pese a su sutileza, de la «comunidad imaginada» que supone la nación ${ }^{5}$.

Centrándonos en el caso mussoliniano y en el sistema de assicurazioni sociali, que el fascismo impulsó, el intervencionismo estatal se concentró en extender los seguros sociales preexistentes a los trabajadores urbanos e industriales (y en una medida mucho menor, a sus familias). Se encajó este sistema en las directrices del ideario y de la cosmovisión fascista y se mantuvieron, al mismo tiempo, las líneas maestras de la previ-

\footnotetext{
3 Minesso, 2018.

4 Griffin, 2011.

5 Beramendi y Rivera, 2016
} 
sión social italiana ${ }^{6}$. Uno de los objetivos de este sistema de assicurazioni sociali fue el de sacar a las mujeres fuera de las fábricas, reubicándolas en la esfera estrictamente doméstica y consagrándolas al rol de madres y amas de casa. El fascismo buscó así liberar puestos de trabajo para los hombres, considerados los jefes del núcleo familiar. Esta concepción de «familia ideal», en clave dictatorial aunque también con un fuerte componente religioso, es una de las notorias confluencias entre los regímenes de Mussolini y Franco. En el caso español, además, el planteamiento «hombre ganador de pan / mujer ama de casa» persistió a la caída de los totalitarismos occidentales tras el fin de la segunda guerra mundial, constituyendo uno de los elementos característicos de la forma de entender la «familia ideal española» ${ }^{7}$.

El fomento de la natalidad, como forma de conseguir vigorizar y proteger la nación frente a potenciales enemigos, fue otra de las señas de identidad de los totalitarismos (aunque no fuera exclusiva de estos). Para ello, el régimen de Mussolini estableció los premios de natalidad, se instituyó el día nacional de la madre y del niño, se constituyeron préstamos de nupcialidad y se establecieron prestaciones económicas y exenciones fiscales orientadas al fomento de las familias numerosas. Durante los más de 20 años que duró el régimen, aunque especialmente durante la segunda guerra mundial, los niños de aquella Italia fascista fueron presentados por la propaganda mussoliniana como los soldados del mañana; como la fuerza y la potencia de aquella Italia presente y futura. Las medidas orientadas a potenciar la natalidad y la nupcialidad se agruparon en el sistema de assegni familiari fascista, que el franquismo imitó fielmente al instituir, en 1938 y todavía en guerra, el régimen general de subsidios familiares.

Tanto en España como en Italia, la legislación se esforzó pues en convertir a las mujeres en sujetos dependientes del cabeza de familia, y con una función social que iba poco más allá de un rol, impuesto desde arriba, de esposas y madres. En este contexto de subyugación femenina, avalada, legislada y legitimada por el Estado, cabe ubicar iniciativas como la Opera Nazionale Maternità e Infanzia que, creada en 1925 y reformada en los inicios de los años 30, se orientó a proteger a las madres en un marco legislativo en el que aparecían como menores de edad, como elementos débiles susceptibles de ser tutorizados y protegidos en tanto que engen-

6 Silei, 2003.

7 Nielfa, 2003 
dradoras de las nuevas generaciones que harían de Italia una nación más potente, grande y fuerte ${ }^{8}$.

Mediante sus políticas sociales, los fascismos pretendieron relativizar la importancia de la privación de derechos políticos y civiles impuesta a su población, transmitiendo la imagen de una sociedad empapada de Estado y de un Estado empapado de sociedad. Se planteaba un bloque compactado y sujetado por el pretendidamente férreo corsé del Estado, en el que la sociedad se insería en el aparato totalitario aunque no quisiera, participando de sus estructuras, de sus exigencias económicas y también de sus beneficios, con la condición de que fuera dócil y obediente ${ }^{9}$. Así, las dictaduras modernas, a través de las herramientas de las que se apropiaron (entre ellas, las políticas sociales) ofrecieron una alternativa totalitaria al problema que había surgido, para el liberalismo, en la primera posguerra mundial: la inclusión de las masas en el «continente» de los Estados ${ }^{10}$.

El régimen de Mussolini construyó un entramado de vocación intervencionista en la vida pública y privada de los italianos e italianas, con la convicción de que la propaganda, la formación escolar, el control del mundo del trabajo y del tiempo libre, y la política social serían los vehículos hacia el consenso. En este contexto se crearon la Opera Nazionale Balilla dirigida a la juventud (llamada, desde 1937, Gioventù Italiana del Littorio, y la Opera Nazionale Dopolavoro, destinada a la gestión del ocio en clave fascista ${ }^{11}$. En la misma línea de concentración y encuadramiento social, en 1933 se creó el Istituto Nazionale Fascista della Previdenza Sociale (en adelante, INFPS) que confirmó la unión entre fascismo y política social (y la subordinación de la segunda al primero). En torno a este se vertebró, desde entonces, una previsión social fascista que tendió a beneficiar más a los elementos más leales el régimen, como los empleados públicos y la pequeña burguesía, y menos a elementos «periféricos» a las prioridades fascistas, como el mundo agrícola, en general, y los jornaleros en particular ${ }^{12}$.

El INFPS quiso convertir en icónicas, a fuerza de una intensa propaganda, algunas de sus «conquistas sociales». En este sentido, destacan campos como la lucha contra la tuberculosis y la protección a la maternidad y la

\footnotetext{
8 De Grazia 1993.

9 Dogliani, 2017.

10 Mason, 1993.

11 López Gallegos, 2004.

12 Giorgi, 2004.
} 
infancia. El INFPS fue, además, el ente gestor (y subvencionador, usando las recaudaciones de los trabajadores destinadas a seguros sociales), de otros ámbitos alejados a priori del ámbito de la previsión social, y vinculados a la vocación expansionista-imperialista del fascismo, como la «colonización» de Libia ${ }^{13}$. El franquismo imitó también esta tendencia al enaltecimiento de algunas esferas de sus «políticas sociales» convirtiendo en simbólicos, eso sí, ámbitos distintos. Entre ellos, destacó el Seguro Obligatorio de Enfermedad (SOE), que fue deliberadamente presentado como una «conquista social» sin precedentes, además de cómo una útil herramienta de encuadramiento sociopolítico impulsada mediante el potencial difusor y editorial del Instituto Nacional de Previsión (en adelante, INP) ${ }^{14}$.

El inicio de la segunda guerra mundial inauguró en países como Alemania e Italia, la transformación de un «Welfare State totalitario» a un «Warfare State»: un Estado que puso su fortaleza, su proyección industrial y demográfica, y su intervención en el bienestar y la salud de su población, al servicio de una guerra contra un enemigo al que había que someter, tanto ideológica como militarmente ${ }^{15}$.

Durante el desarrollo de la segunda guerra mundial, y atendiendo a modelos de políticas sociales gestados en diferentes países con de colores políticos diversos, William Beveridge comenzó a reflexionar sobre alternativas sociales para intentar superar el modelo anterior a 1929, y que neutralizaran los fantasmas de aquellos regímenes totalitarios que habían conseguido ascender en Europa gracias a la gran crisis. Así, Beveridge partió de la idea de que, para inmunizar a Europa del virus fascista, no bastaba con derrotarlo militarmente si no que la clave era ganarse a la población, convirtiéndola en ciudadanía, y demostrando la fuerza inclusiva de una democracia más social: renovada. Para ello, las políticas sociales públicas asomaron de nuevo como uno de los mejores mecanismos de vertebración y fortalecimiento. En 1942 Beveridge presentó al parlamento británico su informe Social Insurance and Allied Services, en el que propuso un nuevo modelo de interacción, en lo que a política social se refiere, entre lo público y lo privado. Pocos años después, sus pautas se convirtieron en el modelo seguido por gran parte de una Europa postbélica que repensaba la forma de hacer política social tras la caída de los grandes totalitarismos.

\footnotetext{
13 Piraino, 2015.

14 Marín y Fernández, 2017.

15 Rapini, 2010.
} 
Beveridge estableció el eje de su preocupación en el concepto «Seguridad Social», que había sido acuñado durante el New Deal estadounidense para referirse a los seguros sociales obligatorios, y dotó a este concepto de un nuevo y más ancho significado: el de la responsabilidad y el deber, de los poderes públicos, de garantizar una protección a sus sociedades contra cinco grandes amenazas: la miseria, la enfermedad, la ignorancia, la falta de una vivienda digna, la ociosidad vinculada al desempleo y la dependencia.

En el plano práctico de la previsión social, esta ambiciosa declaración de intenciones se concretaría en un sistema de Seguros Sociales unificado encargado de suministrar las rentas de sustitución a los trabajadores que perdieran sus rentas profesionales; un Servicio Nacional de Salud que dispensara asistencia sanitaria gratuita a toda la ciudadanía; un mecanismo de ayuda familiar orientado al fomento de la natalidad, y una institución denominada «Asistencia Nacional» para proveer a la subsistencia de quienes demostraran una grave situación de carencia de recursos ${ }^{16}$.

\section{Elementos confluyentes y divergentes entre las políticas sociales de Franco y Mussolini}

En lo que respecta a nuestro acercamiento al fenómeno de las políticas sociales, en clave española e italiana y en el ámbito cronológico propuesto, cabe mencionar que sobre el proceso de vertebración de un sistema de seguros sociales estatal durante el régimen franquista y sobre la incidencia mayor o menor de este en términos políticos, sociales y económicos, la historiografía española se ha asomado a la temática a través de múltiples prismas. Así, desbordando las imprescindibles monografías sobre la materia ${ }^{17}$, producto/consecuencia de la importancia de los debates sobre los márgenes del Estado del Bienestar en nuestro mundo actual, las diferentes corrientes de investigación han partido de líneas como el proceso de vertebración de la previsión social española en un contexto cronológico amplio $^{18}$, la variable coercitiva/aglutinadora/nacionalizadora de esta «política social del régimen» ${ }^{19}$, su grado de implantación y su ten-

\footnotetext{
16 Whiteside, 2003.

17 Castillo y Ruzafa, 2009.

18 Comín, 2007; Pons y Silvestre 2010.

19 Cenarro 2005; Molinero 2005.
} 
dencia a la discriminación de determinados colectivos laborales ${ }^{20}$, su ubicación en un contexto sociolaboral, el del primer franquismo, altamente precario $^{21}$, sus elementos excluyentes en clave de género ${ }^{22}$, o su incidencia en variables de asociacionismo popular preexistentes ${ }^{23}$. Así mismo, el acercamiento llevado a cabo por la historiografía italiana a la historia de los seguros sociales es un objeto de estudio que se halla en un proceso de notoria dinamización, ante los grandes huecos con los que el conocimiento histórico se encuentra y ante el creciente interés que la materia suscita $^{24}$.

Respecto a los principales entes gestores de la previsión social en España e Italia durante el periodo analizado, el INP y el INFPS, el análisis que la historiografía ha realizado sobre el desenvolvimiento de ambos también es reseñable. Pero los acercamientos realizados han tendido a circunscribirse a la esfera de las culturas políticas, a su vinculación con dinámicas internas/estatales, y al análisis de vertebración administrativa y de aspectos operativos ${ }^{25}$. Son escasos, pues, los ejemplos de estudios preocupados por las variables sociales o nacionalizadoras tanto del INP como del INFPS.

En lo que respecta al INP, había sido fundado en 1908 con una vocación deliberadamente apolítica y con la función de fomentar la previsión y el ahorro entre las clases populares, en un momento todavía de definición de los márgenes de actuación del Estado en la cuestión social. Durante sus primeras fases el INP fue asumiendo, de forma lenta si atendemos a los ejemplos de otros países europeos, la necesidad de una participación activa del estado en el fomento del bienestar de la ciudadanía. Pasando, así, en un largo proceso que abarcó los años 10 y 20 del s. Xx, de un modelo de «libertad subsidiada», a otro tendente al establecimiento de seguros sociales obligatorios coordinados por «lo público».

La Guerra Civil hizo que el INP, hasta entonces deliberadamente apartado de los vaivenes políticos del país, se politizara. En julio de 1936, El Frente Popular depuró a cargos dirigentes en el INP «desafectos», derivando en el cese de algunos miembros históricos del INP,

20 González Murillo, 1998.

21 Vilar Rodríguez, 2006.

22 Bock, 1996; Alejandre, 2009.

23 Uría, 2005; Maza Zorrilla, 2008.

24 Vinci, 2011; Mattera 2012; Fargion, Ferrera y Jessoula, 2012.

25 Álvarez Rosete, 2003; Montero 2009; Silei, 2003; Giorgi, 2004; Melis, 2018 
que habían mantenido una posición ambigua, distante o crítica respecto a algunos elementos del sistema republicano. Entre ellos, cabe destacar a católicos sociales como José Jordana de Pozas, vinculado el INP desde los años 20 y una de sus figuras más carismáticas ${ }^{26}$. El final de la guerra y la instauración de la dictadura en España confirmaron y vigorizaron esta politización de la institución. En un primer momento (1938-1941), la gestión del INP estuvo canalizada a través del catolicismo social, cuyos representantes pasaron a ser mayoría en la dirección del Instituto. Este fue el periodo de la puesta en marcha del régimen de subsidios familiares y de la reformulación de un buen número de seguros sociales prefranquistas, que el régimen se esforzó en presentar como logros propios. La llegada del falangista José Antonio Girón de Velasco al Ministerio de Trabajo, en mayo de 1941, marcó una nueva fase: la composición del órgano directivo del INP se reestructuró, pasando a ser Falange el elemento predominante.

El viraje del Instituto hacia aquel falangismo fascistizado hizo que también se adoptaran nuevas pautas discursivas y propagandísticas, que los «grandes nombres» del INP asumieron en bloque. El componente social de los seguros sociales, eje vertebrador de la acción del Instituto hasta entonces, se relegó a un segundo plano, eclipsado por un fin último que todo lo envolvía: el fin político, entendido este como el ideal de aquel Estado nacionalsindicalista totalitario:

En el Estado totalitario, las fuerzas e instituciones sociales, las entidades y los hombres, las empresas y los servicios están como imantados por el fin estatal. Sin dejar de servir cada uno su objeto o su destino propio, todos ellos sirven - además - el fin superior del Estado, al que han de orientarse, del que deben estar permanentemente penetrados o saturados (...). Los Seguros sociales no constituyen excepción de esta regla fundamental. Y, por ende, la primera consecuencia del principio de unidad es la de que el fin político de los seguros sociales esté ordenado y conjugado con el fin político general ${ }^{27}$.

En la vertiente analítica que nos ocupa, el caso italiano tiene considerables similitudes con el español, fruto de notables interacciones y confluencias. El INFPS surgió en 1933, como la apropiación reformulada y

26 Marín, 2013.

${ }^{27}$ Luis Jordana de Pozas, «El principio de Unidad y los Seguros Sociales», Boletín de Información del INP, n. ${ }^{\circ}$ 7-8 (julio agosto), 1941. 
adaptada a la política fascista de una entidad anterior (la Cassa Nazionale per le Assicurazioni Sociali, vigente desde 1919). La actual sede romana del todavía operativo Instituto (que obviamente ya no mantiene esa de «F» de Fascista en su denominación) contiene una gran cantidad de documentación sobre los seguros sociales durante el fascismo, de corte tanto propagandístico como estadístico. El estudio de las publicaciones derivadas de su servicio editorial muestra la gran atención que desde Italia se mostró al avance de los seguros sociales en España, a través de la publicación de textos sobre la «política social de Franco» de autores como Severino Aznar o Luis Jordana de Pozas. También cabe destacar la labor propagandística de dos presidentes del INFPS durante el periodo analizado: Bruno Biagi (1935-1939) y Ferruccio Lantini (1939-1943).

En clara sintonía con la concepción de la política social de Jordana de Pozas y Girón, también en el caso italiano los seguros sociales del fascismo se enmarcaron, hasta el final de la segunda guerra mundial, en un contexto muy concreto: el del ideario fascista y su concepción corporativa del mundo del trabajo. Tal y como se exponía en la propaganda falangista más fascistizada, la política social del régimen de Mussolini era presentada como una consecuencia natural del corporativismo fascista, y como un efecto intrínseco a su supuesto consenso. Era pues, esencialmente, un ámbito subordinado al fin político del fascismo y a sus pretensiones. Entre estas pretensiones, destacaba el fomento de la natalidad para conseguir mayor potencia demográfica, o la protección de los trabajadores industriales para conseguir mayor potencia industrial. La propaganda del INFPS reivindicó insistentemente esta subordinación de lo social a lo político, planteada como inherente al mismo sistema fascista:

Concepción fascista de la seguridad social.

En el régimen fascista, la previsión social es uno de los pilares fundamentales en los que se apoya la protección y la defensa social del trabajo. Alta manifestación del espíritu de colaboración que la Carta del Trabajo ha introducido en el orden corporativo, esta previsión social opera, se perfecciona, y se desarrolla de acuerdo a las directrices del fascismo: en favor de los trabajadores, pero en función siempre de las superiores exigencias de la nación.

Situada en un nivel superior de colaboración nacional, la previsión social ya no es producto de una conciliación más o menos completa de intereses en conflicto, sino una expresión espontánea de las fuerzas de producción, que actúa armónicamente en el marco de la acción corporativa. 
La previsión social fascista, estrechamente coordinada con todas las manifestaciones de la política social, desde las demográficas hasta las políticas, asume una importancia fundamental en la actividad del Estado fascista que ha establecido la nueva dignidad del trabajador ciudadano, depositario del más alto deber social, después de las armas: el deber social del trabajo.

El Istituto Nazionale Fascista della Previdenza Sociale no es sólo el máximo organismo en el cual se coordinan y unifican muchos sectores de seguros, si no que también es un potentísimo medio de acción política que, en sus objetivos, estructura y métodos, está perfectamente en línea con la doctrina del estado fascista y corporativo ${ }^{28}$.

Sin embargo, a este «paquete básico» de propaganda a través de los seguros sociales, el fascismo añadía otros elementos distintivos de las potencias totalitarias que entrarían en guerra a partir de 1939. Uno de ellos, el concepto mussoliniano de Impero incidió en la necesaria expansión geográfica de la Italia fascista como mecanismo de vigorización nacional. La extensión del Impero hacía necesario un fortalecimiento de la stirpe o de la razza italiana que, se conseguiría mediante un pueblo italiano más numeroso, sano y fuerte, gracias al sistema de assicurazioni sociali. Por lo tanto, la política social no era sino un elemento subordinado a estos otros fines políticos/nacionales más importantes. Así es posible en-

28 Traducción propia, del original: Concezione fascista della previdenza sociale. Nel regime fascista la previdenza sociale è uno dei cardini fundamentali su quali poggiano la tutela e la difesa sociale del lavoro. Alta manifestazione di quello spirito di collaborazione che la Carta del Lavoro ha posto dell'ordine corporativo, essa opera, si perfeziona, si sviluppa nell'ambito a secondo le direttive dell'ordenamento stesso: nell'interesse dei lavoratori, ma in vista sempre delle superiori esigenze della nazione. Posta su di un piano superiore di collaborazione nazionale, la previdenza sociale non è più un prodotto della conciliazione più o meno completa di interessi fra di loro contrastanti, ma espressione spontanea delle forze della produzione, armonicamente agenti nel quadro dell'azione corporativa. La previdenza sociale fascista - strettamente coordinata a tutte le manifestazioni della politica sociale, da quelle di ordine demografico e a quelle esencialmente politiche- assume importanza fondamentale nell'attività dello Stato fascista che ha instaurato la dignità nuova del cittadino lavoratore, depositario del più alto dovere sociale dopo quello delle armi: il dovere sociale del lavoro. L'Istituto Nazionale Fascista della Previdenza Sociale non costituisce soltando il massimo organismo nel quale sono co-ordinati ed unificati numerosi settori assicurativi, ma è anche un potentissimo mezzo di azione politica, che, nelle sue finalità, nella sua struttura e nei suoi metodi, è perfettamente in linea con la dotrina dello stato fascista e corporativo. En Al di là dal lavoro, al di là dal salario. INFPS, Roma, 1940 
tender, por ejemplo, que el INFPS se convirtiera en ente gestor de la colonización agrícola de Libia ya desde el año de su surgimiento, en 1933, y a iniciativa de Giuseppe Bottai. Se armonizaba así la lucha contra la desocupación a través del establecimiento de colonias agrícolas en Libia, y la proyección del Impero a través de la extensión física de la política fascista más allá de las fronteras de Italia ${ }^{29}$. La actividad del INFPS en Libia, como la construcción de establecimientos para colonos, adecuación de terrenos para el cultivo, construcción de pozos, etcétera, se convirtió en otro mecanismo importante para difundir las «grandes conquistas sociales» del fascismo a través del servicio editorial del Instituto. La propaganda y el fomento del seguro obligatorio contra la tuberculosis, creado por el fascismo en 1933, se erigió también en una plataforma recurrente para vertebrar y difundir esta noción de política social subordinada a las grandes esencias del fascismo:

Desde 1922 en adelante, lentamente primero, y después con un ritmo cada vez más alto como resultado de la reversión revolucionaria del fascismo, los postulados de un sistema político que había amenazado con arruinar a la nación cayeron uno a uno (...)

A estas alturas, el concepto de Nación, el más alto símbolo de las aspiraciones de un pueblo, una síntesis de su pasado, su presente y su futuro, ha penetrado cada vez más en el alma del individuo. Una preciosa consecuencia de este gran fenómeno psicológico ha sido la revalorización del concepto de linaje, el reconocimiento del valor que, como resultado del poder nacional, se otorga al tenor físico del pueblo (...)

Esta comprensión del valor de la raza, y por lo tanto de su salud, ya constituía, por sí mismo, un factor precioso en la batalla contra la tuberculosis. (...)

El fortalecimiento de la Nación, en su plano imperial, requiere una atención y protección cuidadosa de la salud de la raza, especialmente en relación con las enfermedades sociales: en el primer lugar de todas ellas situamos la tuberculosis ${ }^{30}$.

${ }^{29}$ Cresti, 1996.

${ }^{30}$ Fragmentos del discurso de Bruno Biagi, presidente del INFPS, ceremonia inaugural de las manifestaciones nacionales antituberculosas del XV año de la Era Fascista, y II del Imperio (4 de abril de 1936), en Difesa Sociale, n.3, marzo de 1937. La traducción es de realización propia, y el texto original, el siguiente:

Dal 1922 in poi, lentamente prima, e quindi con un moto sempre più accelerato, per effetto del rivoluzionario capovolgimento dal Fascismo, cadevano ad uno ad uno i postulati di un sistema político che aveva minacciato di rovina la Nazione (...) Ormai il concetto 


\section{Reflexiones finales, y proyección de las políticas sociales en España e Italia tras la Segunda Guerra Mundial}

Entre finales de los años 30 y mediados de los 40, y en un contexto internacional de una complejidad y efervescencia ideológica sin precedentes, los regímenes de Franco y Mussolini dieron forma a unos sistemas de seguros sociales que se adaptaron a la naturaleza totalitaria de ambos regímenes y a los elementos característicos propios de cada país.

En lo que respecta a este texto, el manejo y estudio de fuentes derivadas del INP y del INFPS ha permitido revelar que la Italia de Mussolini y la España de los primeros años del franquismo compartieron una tendencia a presentar sus políticas sociales como puentes hacia la consecución de un objetivo último al que se subordinaban: el afianzamiento masivo de una concepción política totalitaria, al estilo italiano (Partito Fascista) y al estilo español (Falange). Los servicios editoriales del INP español y el INFPS italiano se convirtieron en herramientas para llevar a cabo esta labor, a través de numerosos libros y folletos propagandísticos y estadísticos, y de diferentes publicaciones periódicas (Nuestra Obra, o Boletín Oficial del INP fueron algunas de las publicaciones periódicas importantes para el caso español, o Rivista le assicurazioni sociali, Al di là dal lavoro, al di là dal salario y Difesa Sociale, para el caso italiano).

La política social fascista fue, en su fase inicial, la principal fuente de inspiración para el franquismo. La concepción corporativa del fascismo encajaba como un guante en el ideario falangista, y una política agresiva de fomento de la nupcialidad y la natalidad se antojaba imprescindible tanto en un país, como el franquista, que acababa de nacer de una guerra, como para otro, el mussoliniano, que se preparaba para otra.

Ambos regímenes no plantearon los seguros sociales como iniciativas limitadas a incrementar el bienestar de los ciudadanos. Por el contra-

\footnotetext{
di Nazione, simbolo più alto delle aspirazioni di un popolo, sintesi del suo passato, del suo presente e del suo futuro, penetrava sempre più nell'animo dei singoli. Preziosa conseguenza di questo grandioso fenomeno psicologico doveva essere la rivalutazione dal concetto di stirpe, il riconoscimento del valore che asume, agli effetti della potenza nazionale, il tenore físico del popolo (...). Questa comprensione del valore della stirpe, e quindi della sanità di essa, costituiva già, per sè solo, un fattore prezioso nella battaglia contro la tubercolosi. (...) Il potenziamento della Nazione sul piano imperiale esige più attenta cura e più provvida tutela della sanità della razza, specie in rapporto alle malattie sociali: prima fra tutte la tuberbolosi.
} 
rio, estas políticas sociales totalitarias carecían de sentido si no atendían a un horizonte mayor, único y más trascendente: el del éxito de las revoluciones fascista y nacionalsindicalista. El INP y el INFPS fueron los entes responsables de divulgar esta concepción de lo social subordinado a lo político, instrumentalizando la acción social estatal como mecanismo para intentar fomentar adhesión popular y forzar consenso.

Partiendo de este elemental tronco común, ambos regímenes tuvieron ingredientes distintos según la estructura ideológica que ambos fueron forjando. En este sentido, factores como la formulación de la proyección geográfica exterior del fascismo, o su formulación, inspirada en la Alemania nazi, del concepto raza o estirpe a partir de 1938 (Il manifesto della razza), fueron elementos que se incorporaron a la propaganda sobre seguros sociales del INFPS y que vertebraron una determinada subordinación de lo social a lo político. El factor bélico hizo, además, que en el caso italiano el objetivo de la victoria se convirtiera en otro factor decisivo y desequilibrante, que convirtió el welfare totalitario de la Italia fascista en un warfare.

Podría parecer que las políticas sociales totalitarias tuvieron un desarrollo y desenvolvimiento genuinos, diferente al de sistemas políticos de otro color. Estos países totalitarios se comportaron de manera oportunista, modelando un sistema de seguros sociales (y una forma de entender y de proyectar esos seguros sociales) que, pese a no serlo necesariamente, pareciera auténticamente propio y revolucionario para, después, convertir esa política social en una herramienta para acercarse a la consecución de sus objetivos políticos. Sin embargo, y aunque fuera de forma enmascarada, franquismo y fascismo se alimentaron también de los avances que en política social estaban ocurriendo en el contexto internacional. Reflejo de ello es que ambos regímenes imitaron elementos del programa de William Beveridge proyectando, por ejemplo, propuestas de unificación de los seguros sociales antes del desenlace de la segunda guerra mundial. Esta atención a lo internacional, deliberadamente opaca, se tornó manifiesta tras el final de la segunda gran guerra. Así, en ambos países, en distintos contextos aunque por motivos similares, Beveridge se convirtió en el nuevo referente y en la forma de mostrar al exterior que, tanto la España franquista post-totalitaria como la balbuceante Italia republicana, querían desmarcarse de su camino anterior y encajar lo mejor posible en el nuevo mundo emergente.

En España, el desenlace de la Segunda Guerra Mundial y la derrota de los totalitarismos con los que el Movimiento se había venido identificado durante parte de la contienda, provocó que Franco acometiera una reestructuración 
en los principales órganos políticos del INP a finales de 1945, tendente a atemperar la presencia del falangismo en ellos, que se había convertido en la dominante en el INP desde que José Antonio Girón de Velasco llegara al Ministerio de Trabajo, en 1941. Pocos meses después del inicio de este «proceso de readecuación», en marzo de 1946, se produjo la visita al INP de William Beveridge ${ }^{31}$. Esta visita impulsó la reapertura de la principal publicación periódica del INP, el Boletín de Información del INP, que desde 1943 venía orientándose mayoritariamente a ensalzar las virtudes del Seguro Obligatorio de Enfermedad puesto en marcha con el profundo sello falangista de José Antonio Girón de Velasco, y hacia el planteamiento de ambiciosos y poco realistas proyectos como la unificación de los seguros sociales (la aspiración a lo que el franquismo llamaría un Seguro Total, que ya había sido planteado en 1941 y que tardaría más de dos décadas en cristalizar, a través de la Ley de Bases de la Seguridad Social) ${ }^{32}$.

De la mano de esta visita, se aprecia también un cambio que se considera de gran importancia en la nueva política aperturista (o de lavado de cara) por la que se apostó en el seno del INP a instancias de la nueva composición de su consejo: el Boletín de Información del INP, la principal publicación periódica producida por el Instituto, que entre 1941 y 1946 había sido dirigida por Girón, y que se había erigido en una de las principales herramientas propagandísticas en línea con los postulados falangistas del Instituto entre aquellos años, pasó desde 1947 a estar dirigida por Jordana de Pozas, y a denominarse Revista Española de seguridad Social. En unas páginas que, a modo de presentación, Jordana introdujo en las líneas iniciales del primer número de la revista, aludía a la significación del nombre de la nueva publicación, por ser universalmente admitido por las naciones, para señalar una actuación de lucha contra la miseria. El cambio en el discurso era evidente, y el contexto internacional en materia de seguros sociales, que en la publicación anterior no había pasado de ser un mero objeto de análisis orientado al ensalzamiento del sistema español, pasó a ocupar un lugar central en la revista, y a exponerse como referente ${ }^{33}$.

Para rematar el viraje en el INP, se creó un nuevo órgano dentro del mismo, el Servicio Exterior y Cultural, que se encomendó también a Jor-

31 Boletín de Información del INP, n. ${ }^{\circ}$ 3, (marzo de 1946).

32 A modo de ejemplo: Ginés de Haro: Unificación de los seguros sociales, seguro social único y seguro total. Boletín de Información del INP, n. 7 (Julio 1946).

33 Remitimos, para aquellos interesados en la consulta de esta revista, a la biblioteca del Instituto Nacional de Gestión Sanitaria (INGESA) (sign. C 000850). 
dana de Pozas, y más tarde a Carlos Martí Bufill. Además de la edición de la nueva publicación, entre los cometidos de este nuevo organismo figuraba estrechar los vínculos por las principales corrientes internacionales en materia de Previsión Social pública. De este modo, el franquismo quiso recuperar, despojando de su discurso todo contenido de impronta falangista, al Jordana de Pozas anterior a 1941, convirtiéndolo en principal referente de esta nueva fachada que el régimen pretendía proyectarse al exterior, y en principal embajador internacional del régimen en materia - ahora - de Seguridad Social. De este modo, si la impronta falangista característica de los textos de Jordana de Pozas había sido patente entre 1941 y 1946, a partir de 1947 cambió radicalmente, entrando incluso en colisión con máximas que Girón había proclamado, y con las que Jordana antes había comulgado:

Acostumbrados como estamos a contemplar el Seguro Social encarnado concretamente en una legislación, en unas instituciones y en unas realidades determinadas, pudiéramos creer que, por su misma naturaleza, ha de tener carácter local o nacional. Sería un craso error. (...)

Por mucho que se quiera magnificar y exaltar la acción, la acción por sí sola, abandonada a su mero impulso de obrar, no es más que una burda y estéril violencia sobre los hombres y las $\operatorname{cosas}^{34}$.

La emergencia de esta nueva orientación discursiva, sin dejar de alabar las virtudes del régimen en su labor de promoción de un sistema de seguros sociales público en unas condiciones económicas desfavorables ${ }^{35}$, supuso que se asumiera una actitud de eclecticismo respecto a las diná-

${ }^{34}$ Luis Jordana de Pozas: La Seguridad Social en el orden internacional. Conferencia correspondiente al Ciclo organizado en el Plan de Formación profesional para funcionarios del I.N.P., gráficas ORBE, Madrid, 1954, pp. 5 y 7.

35 El recurso a este argumento comienza a usarse con marcada intensidad en 1947, fundamentalmente aparejado a publicaciones a las que se presuponía cierta proyección exterior, como elemento justificador de la no aplicación en España de un sistema unificado y universalista de Seguridad Social. Franco contribuía también, de puertas adentro, a dar carpetazo al aire triunfalista que había presidido la propaganda sobre seguros sociales durante la primera mitad de los años 40, y a conectar con los postulados sobre seguridad social de las principales democracias capitalistas, y sostenía en 1947: Nosotros iremos al Seguro Total, pero para ir al Seguro Total y que no sea una ruina para la Nación, antes hemos de asegurar el trabajo para todos, hemos de poner en marcha a España entera, y cuando hayamos puesto a España entera en movimiento y hayamos reanimado su economía y creado fuentes numerosas de trabajo, cuando el Seguro de Paro afecte nada más que a aquelllas desgracias ocasionales o a aquellas crisis de coyunturas inevitables, entonces iremos al 
micas internacionales punteras en torno al concepto de Seguridad Social, asociada a la ya mencionada vocación teóricamente aperturista que buscaba la legitimación, al menos parcial, del régimen en el contexto internacional. Esto no hizo, sin embargo, que algunos de los elementos más afines a Falange variaran el cauce de su discurso en lo tocante a previsión social pública, lo que nos lleva a plantear le existencia de dos discursos, marcadamente diferenciados, en lo referente a previsión social pública, especialmente a partir de la puesta en marcha del nuevo Boletín del INP en 1947. Mientras que el aperturismo abanderado por el reconvertido Jordana de Pozas, patente en los contenidos del Boletín a partir de 1947, pero también en otros abundantes textos posteriores a este año ${ }^{36}$, exteriorizaba el nuevo interés del régimen franquista por mostrar una cara más amable que facilitara al menos un relativo encaje en el nuevo occidente capitalista postbélico ${ }^{37}$, el discurso que mantendrán Girón y otros falangistas vinculados al INP, parcelado a folletos cuya difusión quedaba fuera de la nueva revista, se convirtió en símbolo reivindicativo de un falangismo que, como en otros ámbitos institucionales, se resistía con uñas y dientes a perder su protagonismo en el panorama político franquista ${ }^{38}$.

También en Italia, obviamente, la derrota del fascismo redefinió la forma de entender y de proyectar la política social. La transición de una

seguro del Paro y al Seguro Total. «Discurso de Franco en Langreo», en Revista Española de Seguridad Social, n. ${ }^{\circ}$, abril 1947.

36 Los textos manejados en esta línea son numerosos. Algunos ejemplos destacables, a modo ilustrativo: Luis Jordana de Pozas: La Seguridad Social en el orden (...); Carlos Martí Bufill, Tratado comparado de Seguridad Social, Ministerio de Trabajo, INP, Madrid 1951; Juan Antonio de Cuenca, Gestión de la Seguridad Social, INP, Madrid, 1951. Asimismo, en la Revista Española de Seguridad Social: Federico López Valencia, «El presupuesto de la Seguridad Social», septiembre 1947; León Leal Ramos, «La Unificación de los seguros sociales y el seguro total: dos etapas»., octubre de 1947; Carlos Martí Bufill; «La unificación del campo de aplicación de los seguros sociales», julio-agosto de 1948.

37 Este tipo de maniobras aperturistas cristalizarán en la incorporación del régimen, a pesar de su condición de autoritario, a instituciones internacionales vinculadas a máximas democráticas como la Organización de las Naciones Unidas, en 1955, o la Organización internacional del Trabajo (OIT), a la que España se reincorporó en 1956 tras un largo paréntesis de 15 años.

38 Una pequeña muestra de ejemplos: Hermenegildo Baylos Corroza: El ideal de previsión en la politica social española. INP, Madrid 1949; Consignas y consideraciones políticas sobre Previsión Social. Madrid, Sucs. de Rivadeneyra S.A., 1953 (recoge los discursos de notorios falangistas vinculados al INP como José Antonio Girón de Velasco, Fernando Coca de la Piñera, Pedro Sangro y Ros de Olano, Carlos Pinilla Turiño, pronunciados durante la I Asamblea General del Instituto Nacional de Previsión, en 1953). 
dictadura a una democracia cambiaba radicalmente el escenario, pero no el fin perseguido respecto a la dictadura franquista: encajar en el nuevo contexto internacional de la forma menos traumática posible.

Las ideas de Beveridge habían tenido eco en la Italia fascista poco después de que fueran formuladas, aunque con el lenguaje propio de una iniciativa surgida de un país enemigo y en un contexto bélico. La Rivista le assicurazioni sociali publicó, de hecho, un extenso artículo sobre el tema en 1943, con el título Il piano Beveridge: dalla cura alla bara. Ya para ese año, parte del ideario fascista en el que se había basado la razón de ser de los seguros sociales, se tambaleaba: la labor de organización del INFPS en la colonización de Libia se interrumpió en 1943, con la pérdida de la colonia. El fascismo se derrumbaba, y con él su concepción de política social.

A finales de 1943 Le assicurazioni sociali dejó de publicarse, siendo 1944 un año de transición en el que, como consecuencia de la fase terminal del fascismo, la labor del INFPS (tanto general, como editorial) se paralizó. Un año después, y tal y como sucediera con el caso español, la revista se refundó con un nuevo título - Previdenza Sociale-, y con nuevos contenidos y orientaciones reflejo de la nueva preocupación de Italia por encontrar su lugar en el nuevo mundo. Beveridge y su «Libro Blanco» emergieron como el referente principal al que el país debía mirar, aunque también, y de forma intensa, la URSS, y en menor medida EEUU. El problema del desempleo en el país asomaba como la cuestión más delicada a resolver. La presentación del primer número de la revista ejemplificaba la difícil situación de una posguerra difícil, y de un país al que tocaba redefinir sus referentes:

No es desatinado afirmar que, una vez terminada la guerra, ahora debemos ganar la paz.

Ya no truena el cañón, pero en el agitado escenario de un mundo que todavía no se ha calmado, emergen fermentos innovadores, reivindicaciones de libertad, y exigencias de democracia (...).

En este fervor de actividad, los seguros sociales han adquirido particular importancia como un instrumento adecuado para lograr la seguridad social, la « freedom from want».

Para asegurar esta seguridad social, para asegurarse de que ante cualquier eventualidad exista una protección y cobertura para la ciudadanía, el Gobierno Británico ha promovido estudios del más alto valor (Plan Beveridge) habiéndose expuesto ante la Cámara de los Comunes un sólido proyecto de reforma del sistema de seguros sociales (Libro Blanco) (...). 
Simplemente vamos a señalar que, sea cual sea el régimen económico de la producción social - aquel vigente en los países anglosajones, o el llevado a cabo en la URSS - , la cuestión de la seguridad social se mantiene viva y fresca, ya que es, por su naturaleza, un método de redistribución del dividendo nacional ${ }^{39}$.

\section{Bibliografía}

AlejANDRE, Juan Antonio, (coord.), Estudios jurídicos sobre el franquismo. La familia ideal y otras cuestiones, Dykinson, Madrid 2009.

Álvarez Rosete, Arturo, Social welfare policies in non-democratic regimes: the development of social insurance schemes in Franco's Spain (1936-1950), tesis doctoral inédita, defendida en 2003 en la University of Nottingham.

BERAMENDI, Justo, y RiVERA, Antonio, «La nacionalización española: cuestiones de teoría y método», en Félix Luengo y Fernando Molina (eds.), Los caminos de la nación. Factores de nacionalización en la España contemporánea, Comares, Granada, 2016, pp. 3-32.

Bock, Gisela (coord..), Maternidad y políticas de género: la mujer en los estados de bienestar europeos, 1880-1950, Cátedra, Madrid 1996.

CEnARro, Ángela, La sonrisa de la falange: Auxilio Social en la guerra civil, Crítica, Barcelona 2005.

Comín, Francisco, «El surgimiento y desarrollo del Estado de Bienestar (18831980)», en Salort, Salvador, y Muñoz, Ramiro (eds.), El Estado del Bienestar en la encrucijada, Universidad de Alicante 2007, pp. 67-128.

CRESTI, Federico, Oasi di italianità. La Libia della colonizzazione agraria tra fascismo, guerra e indipendenza (1935-1956), Società Editrice Internazionale, Torino, 1996.

39 Previdenza Sociale, n.1, enero-marzo, 1945. La traducción es propia, y el texto original, el siguiente:

Non è torto a dire che, vinta la Guerra, bisogna ora vincere la pace. Non tuona più il cannone, ma, nell'agitata scena del mondo non ancora placato, tumultuano e premono, contrastati dai superstiti conati dalla reazione, fermenti innovatori, rivendicazioni di libertà, esigenze di democrazia (...). In questo fervore di attività ha assunto particollare rilievo la previdenza sociale quale strumento idoneo a conseguire la sicurezza sociale, la «freedom from want». Per assicurare questa «libertà di bisogno», per garantire cioè qualunque evenienza un reddito adeguato e sicuro a tutti i cittadini, il governo británico ha promosso studi del più alto valore (Piano Beveridge) ed ha sottoposto alla camera dei comuni un progetto ardito di riforma delle assicurazioni sociali (Libro bianco) (...). Ci limiteremo a precisare che, qualunque sia il regime economico della produzione sociale - quello vigente nei paesi anglosassoni o quello realizzato nell' URSS - il problema della previdenza sociale permane vivo e attuale in quanto esso è, per sua natura, un metodo di redistribuzione del dividendo nazionale. 
De GraZIA, Victoria, Le donne nel regime fascista, Marsilio, Venezia, 1993.

Dogliani, Patrizia El fascismo de los italianos. Una Historia Social, PUV, Valencia, 2017.

EsPING-ANDERSEn, Gøsta, The three worlds of welfare capitalism, Princeton University Press, Princeton, 1990.

FArgion, Valeria, Ferrera, Mauro, Jessoula, Matteo, Alle radici del welfare all'italiana. Origini e futuro di un modello sociale squilibrato, Marsilio, Venecia 2012.

GIORGI, Chiara, La previdenza del regime. Storia dell'INPS durante il fascismo, Il Mulino, Bologna, 2004.

GRIFFIN, Roger, Modernismo y fascismo. La sensación de comienzo bajo Mussolini y Hitler, Akal, Madrid, 2010.

GonZÁLEZ MurILlo, Pedro, La política social franquista: el Ministerio de José Antonio Girón de Velasco (1941-1957), tesis doctoral inédita, dirigida por Santiago Castillo y defendida en 1998 en la Universidad Complutense de Madrid.

LóPez GALlegos, Silvia, «El control del ocio en Italia y España. De la Opera Nazionale Dopolavoro a la Obra Sindical de educación y Descanso», Investigaciones históricas: Época moderna y contemporánea 24, 2004, pp. 215-236.

MARíN, Guillermo, «Falange, nacionalización y seguros sociales a través de la labor editorial del Instituto Nacional de Previsión (1941-47)», en España Res publica. Nacionalización española e identidades en conflicto (siglos XIX y $X X)$, Comares, Granada, 2013, pp. 527-536.

MARín, Guillermo, FERNÁNDEZ, Iñaki, «Welfare as totalitarian tool. Fascist Italy and Francoist Spain in the European context», en Ferrán Gallego y Francisco Morente (eds.), The Last Survivor. Cultural and Social Projects Underlying Spanish Fascism, 1931-1975, Sussex Academic Press, Eastbourne, 2017, pp. 137-155.

Mason, Tim, Social Policy in the Third Reich: the working class and the national community, Berg, Oxford, 1993.

MAtTERA, Paolo, (ed.), Momenti del welfare in Italia. Storiografia e percorsi di ricerca, Viella, Roma, 2012.

MAZA ZorriLla, Elena (Ed.), «Dossier Asociacionismo en las dictaduras de la Europa del Sur: (Italia, Portugal y España)» (dossier), Alcores, n. ${ }^{\circ}$ 6, 2008.

MELIS, Guido, La macchina imperfetta. Immagine e realtá dello Stato Fascista, Il Mulino, Bolonia 2018.

Minesso, Michela, «De las políticas sociales al Estado del Bienestar. Sincronías y asimetrías España e Italia en el siglo XX», Ayer, 112 (4), 2018.

Molinero, Carme, La captación de las masas. Política social y propaganda en el régimen franquista, Cátedra, Barcelona, 2005.

MonTERO, Feliciano, «El debate sobre el intervencionismo y el nacimiento del Instituto Nacional de Previsión (INP)», en CASTILLO, Santiago, y RU- 
ZAFA, Rafael (coords.), La previsión social en la historia, Siglo XXI, Madrid, 2009, pp. 171-196.

NIELfA, Gloria, (ed.), Mujeres y hombres en la España franquista: sociedad, economía, política, cultura, Universidad Complutense, Madrid, 2003.

Pons, Jerònia, SILVESTRE, Javier (coords.), Los orígenes del estado de bienestar en España, 1900-1945: los seguros de vejez, desempleo y enfermedad. Prensas Universitarias de Zaragoza, 2010.

RAPINI, Andrea Lo stato sociale, Archetipo Libri, Bologna, 2010.

Silei, Gianni, Lo Stato Sociale in Italia. Storia e documenti. Vol. I. Dall'Unità al fascismo (1861-1943), Lacaita, Manduria/Bari/Roma, 2003.

URía, Jorge, «Asociacionismo y sociabilidad durante el franquismo: del colapso al despertar asociativo», en Ortiz Heras, Manuel, (coord.), Memoria e historia del franquismo, Ediciones de la Universidad de Castilla-La Mancha, Cuenca 2005, pp. 75-100.

VILAR RodRíGUEZ, Margarita, «Estrategias de supervivencia de las familias trabajadoras en el marco laboral hostil de la posguerra civil española (19391958), Sociología del trabajo, n. ${ }^{\circ} 56,2006$, pp. 119-154.

VINCI, Stefano, «Il fascismo e la Previdenza Sociale», en Annali Della Facoltà di Giurisprudenza di Taranto, Anno IV, Cacucci, Bari 2011.

WhITESIDE, Noel, «The Beveridge Report and its implementation: a revolutionary project?»,Histoire@Politique, 24, (2014/3),pp. 24-37.

\section{Financiación}

Este trabajo forma parte de las investigaciones desarrolladas en el marco del proyecto «Nacionalización, Estado y violencias políticas (siglos XIX-XXI)», apoyado por el Ministerio de Economía y Competitividad (HAR2017-83955-P), por el Gobierno Vasco (IT 1227-19) y por la Universidad del País Vasco (UPV-EHU) (GIU 18/107)

\section{Datos del autor}

Guillermo Marín (1983). Doctor en Historia (EHU/UPV, 2014), Postdoctoral Fellow en el Indian Institute of Technology (Indian School of Mines) de Dhanbad (India, 2015-2016), Investigador Postdoctoral en la EHU/UPV y en la Università di Torino (2016-2017), Profesor Laboral Interino (UPV/EHU, 2017-2019), Profesor Adjunto (UPV/EHU, 2019-...). Sus objetos de estudio principales son la historia del mutualismo y de los seguros sociales, en clave de historia social y en perspectiva comparada (España-Italia). Ha publicado numerosos artículos de revista y capítulos de libro en diferentes idiomas, así como el libro Mutualismos. La Previsión Social en Álava durante el franquismo (2017). 